\title{
GAYA KEPEMIMPINAN KEPALA SEKOLAH DALAM PERSPEKTIF PSIKOLOGI
}

\author{
Vonny Angeli Sudharta, Maria Mujiati, Amalia Rosidah, Imam Gunawan \\ Email: vonnysudharta@gmail.com \\ Universitas Negeri Malang, Jalan Semarang 5 Malang
}

\begin{abstract}
The purpose of this study was to describe the characteristics of principal leadership, to describe the psychological characteristics of the principal's leadership, and to design the leadership model of the principal in a psychological perspective. The research was conducted in Public Senior High School 1 Malang. The research method used is qualitative research with case study design. Technique of data retrieval through interview, observation, and documentation. The data analysis used is interactive model analysis. The results show that the leadership characteristics shown by the principal are objective, democratic, friendly, humorous, honest, disciplined, assertive, able to control emotions, appreciate, motivate, have a family attitude to all members, fair, strong and religious. Based on the psychological characteristics of the principal's leadership is a leader who shows the person calm, relaxed, patient, meticulous, not easily affected, and high self-awareness. Principal leadership models in psychological perspectives reflect a attribute sanguine and phlegmatic.
\end{abstract}

Keywords: leadership style, principalship, psychology perspective

\begin{abstract}
Abstrak: Tujuan penelitian ini adalah untuk mendeskripsikan sifat-sifat kepemimpinan kepala sekolah, mendeskripsikan karakteristik psikologis kepemimpinan kepala sekolah, dan merancang model kepemimpinan kepala sekolah dalam perspektif psikologi. Penelitian dilakukan di Sekolah Menengah Atas (SMA) Negeri 1 Malang. Metode penelitian yang digunakan adalah penelitian kualitatif dengan rancangan studi kasus. Teknik pengambilan data melalui wawancara, observasi, dan dokumentasi. Analisis data yang digunakan adalah analisis model interaktif. Hasil penelitian menunjukkan bahwa sifat-sifat kepemimpinan yang ditampilkan kepala sekolah adalah objektif, demokratis, ramah, humoris, jujur, disiplin, tegas, dapat mengontrol emosi, menghargai, motivator, memiliki sikap kekeluargaan pada semua anggota, adil, berpendirian kuat, dan religius. Berdasarkan karakteristik psikologis kepemimpinan kepala sekolah adalah pemimpin yang menunjukkan pribadi tenang, santai, sabar, teliti, tidak mudah terpengaruh, dan kesadaran diri yang tinggi. Model kepemimpinan kepala sekolah dalam perspektif psikologis mencerminkan kepemimpinan yang beratribut sanguin dan plegmatis.
\end{abstract}

Kata kunci: gaya kepemimpinan, kepala sekolah, perspektif psikologi

Keberadaan pemimpin sangat dibutuhkan dalam suatu organisasi, hal ini dikarenakan pemimpin yang akan menentukan arah organisasi akan dibawa. Kepemimpinan sendiri merupakan kegiatan seseorang dalam memengaruhi dan menggerakkan seluruh anggotanya untuk dapat mencapai tujuan yang telah ditetapkan. Kepemimpinan dipahami sebagai kekuatan untuk menggerakkan dan memengaruhi orang (Zainal, dkk., 2014). Pemimpin di lembaga pendidikan adalah kepala sekolah. Kepala sekolah harus mampu menggerakkan semua warga sekolah untuk mencapai tujuan pendidikan.
Hal ini dipertegas oleh Suharsaputra (2016) yang menyatakan bahwa kepemimpinan menjadikan suatu organisasi dapat bergerak secara terarah dalam upaya mencapai tujuan yang telah ditetapkan. Kepemimpinan pendidikan dilakukan pada lembaga pendidikan, dengan tujuan memengaruhi semua warga sekolah melaksanakan tugas dan pekerjaannya dengan baik dan benar sesuai dengan tanggung jawab masingmasing, yang pada akhirnya bertujuan untuk mengembangkan segenap potensi 
yang dimiliki oleh peserta didik (Gunawan, 2015b).

Leadership shown by the principalship determine the success of the school program, whether it can improve the quality of learning in the classroom implemented by the teacher or not (Gunawan, 2015c). Setiap kepala sekolah memiliki gaya kepemimpinan yang berbeda dan tidak ada gaya kepemimpinan yang paling baik atau efektif, karena semua tergantung situasi dan kondisi tiap bawahan. Sebagaimana yang diungkapkan Suharsaputra (2016) yang mengemukakan bahwa seorang pemimpin dapat mencapai tujuan dengan berbagai cara dan gaya dalam memimpin, sesuai dengan kondisi internal serta tantangan eksternal yang dihadapinya, sehingga kepemimpinan yang efektif tidak bisa dikaitkan dengan hanya pada aspek tertentu saja yang dimiliki oleh pemimpin ataupun kondisi lingkungan yang mengitarinya. Wahjosumidjo (2013) menegaskan kepemimpinan dapat dibedakan menjadi empat pendekatan, yaitu: (1) pendekatan psikologis (psychological approach); (2) pendekatan situasional (situational approach); (3) pendekatan perilaku (behavioral approach); dan (4) pendekatan kontingensi (contingency approach).

Kepemimpinan berdasarkan perspektif psikologis artinya memandang sisi psikologis yang dimiliki kepala sekolah dalam hal kepemimpinan, dimana yang menjadi pengamatan dalam psikologis kepala sekolah yaitu cara memotivasi, cara pengambilan keputusan, dan cara berkomunikasi. Psikologi sendiri adalah keadan diri seseorang dimana dapat diketahui dengan kegiatan yang nampak namun ada juga yang bersifat tersirat atau nampak. Hal senada dikemukakan oleh Kusmintardjo (1989) bahwa pemimpin berhasil (efektif) adalah sumber dari kepribadian (personality) pemimpin itu sendiri sebagai seorang insan. Hal tersebut membuktikan bahwa hal yang paling mempengaruhi dalam kepemimpinan kepala sekolah adalah kepribadian kepala sekolah sendiri. Yulk (2001) menegaskan personality traits are considered especially relevant to successful leadershi. Karakter kepribadian dianggap sangat relevan dengan kesuksesan kepemimpinan. Kepemimpinan yang dinilai baik apabila fungsi-fungsi kepemimpinan dijalankan berdasarkan prinsip-prinsip beretika (Gunawan, 2015a).
Kepemimpinan kepala sekolah akan nampak manakala kepala sekolah berinteraksi dengan orang lain, misalnya melakukan percakapan pribadi dengan guru, teman sejawatnya, maupun dengan muridnya (Gunawan, 2014b). Effective principalship are a principalship who are committed to the vision of the school and constantly focuses on learning and teacher performance (Gunawan, 2015c). Good leader is good person (Gunawan dan Benty, 2017). Psikologi kepemimpinan membahas tentang: the personal characteristics of leaders; the nature of the relation between leaders and followers; why do we perceive some people to be better leaders than others; what are the circumstances that evoke leadership qualities in people; and can leadership be taught (Messick dan Kramer, 2005). The psychology dimension of leadership is thought to be uniquely important because of the leaders potential to influence employee and organizational behavior (Ozbag, 2016). The leaders are required to support employee's involvement for accelerating the change in organization (Hussain, dkk., 2016).

The psychology ofleadership is defined as the demonstration of normatively appropriateconduct through personal actions and interpersonal relationships, and the promotion of such conduct to followers through two way communication reinforcement, and decision-making (Brown, dkk., 2005). Rumusan masalah yang ditanyakan dalam penelitian ini adalah: (1) bagaimana sifat-sifat kepemimpinan kepala sekolah? (2) bagaimana karakteristik kepemimpinan kepala sekolah dalam perspektif psikologi? Dan (3) bagaimana model kepemimpinan kepala sekolah dalam perspektif psikologi?

\section{METODE}

Rancangan penelitian yang digunakan dalam penelitian ini adalah penelitian dengan menggunakan pendekatan kualitatif deskriptif dan jenis penelitian studi kasus di SMA Negeri 1 Malang. Lokasi penelitian beralamatkan di Jalan Tugu Nomor 1 Kota Malang Jawa Timur. Sumber data adalah kepala sekolah, wakil kepala sekolah bagian kurikulum, wakil kepala sekolah bagian kesiswaan, wakil kepala sekolah bagian sarana dan prasarana, wakil kepala sekolah bagian hubungan sekolah dan masyarakat, guru, dan 
peserta didik. Teknik pengumpulan data adalah wawancara, observasi, dan teknik dokumentasi. Teknik-teknik tersebut merupakan teknik dasar dalam pengambilan data yang bersifat kualitatif.

Peneliti menjadi instrumen kunci (utama) selama proses pengumpulan data. Kehadiran peneliti di lapangan merupakan salah satu tolok ukur keberhasilan akan pemahaman terhadap fenomena yang terjadi di sekolah, karena pengumpulan data harus dilakukan dalam situasi yang sebenarnya. Ulfatin (2015) menegaskan dalam penelitian kualitatif, manusialah yang bertindak sebagai instrumen kunci atau alat pengumpul data utama. Peneliti sendiri bertindak sebagai instrumen kunci. Peneliti sebagai alat atau instrumen kunci dalam penelitian, sehingga kehadirannya pada latar penelitian mutlak dilakukan.

Analisis data dilakukan saat mulai memasuki lapangan, selama di lapangan, dan setelah selesai di lapangan. Namun, analisis data ini lebih difokuskan selama proses di lapangan bersamaan dengan pengumpulan data. Analisis data kualitatif dilakukan secara bersamaan dengan proses pengumpulan data berlangsung, artinya kegiatan-kegiatan tersebut dilakukan juga selama dan sesudah pengumpulan data (Gunawan, 2014a). Analisis data yang digunakan adalah model interaktif dari Miles, dkk., (2014) yakni: reduksi data, penyajian data, dan verifikasi.

\section{HASIL}

\section{Sifat-sifat Kepemimpinan Kepala Sekolah}

Sifat-sifat kepemimpinan yang ditampilkan kepala sekolah ialah objektif, demokratis, ramah, humoris, jujur, disiplin, tegas, dapat mengontrol emosi, menghargai, motivator, memiliki sikap kekeluargaan pada semua anggota, adil, berpendirian kuat, dan religius. Kepemimpinan yang dimiliki oleh kepala sekolah adalah kepemimpinan profetik. Meskipun demikian, kepala sekolah tetap memperlihatkan dirinya sebagai figure yang tidak membeda-bedakan antara satu dengan lainnya. Kepala sekolah merupakan sosok pemimpin yang demokratis, objektif, ramah, humoris, tidak memaksakan kehendak, mampu memosisikan diri, dan mampu memperlakukan bawahan sesuai dengan pribadi bawahannya. Hal yang menjadi keunggulan kepala sekolah yakni sifatnya yang religius dalam memimpin. Berikut ini adalah cuplikan transkrip wawancara kepada guru.

Peneliti : Apakah Bapak kepala sekolah bisa mengontrol emosi saat menghadapi masalah di sekolah?

Guru : Biasanya Beliau memanggil secara personal. Biasanya pendekatannya lewat religi. Iya, misalnya menghadapi anak ini yang nakal, pasti ada sebabnya, berusaha digali kenapa anak ini seperti itu. Kalau ketemu saya itu mengingatkan untuk sholawat, iya, Al Fatihah, kalau mau mengajar, biar ilmunya barokah.

Kepala sekolah memperlihatkan kepemimpinan yang demokratis. Kepala sekolah berusaha mendekatkan diri dengan warga sekolah. Kepala sekolah juga memiliki kewibawaan untuk dapat mengendalikan bawahannya. Kepala sekolah memimpin dengan kekeluargaan dan merangkul semua warga sekolah, sehingga para guru, staf, dan siswa tidak merasa tertekan dan sangat nyaman. Di samping itu, kepala sekolah juga memiliki latar belakang yang agamis. Kepala sekolah merupakan juga seorang kyai, sehingga kebijakan yang diterapkan juga ditunjukkan dari sisi agamanya. Kepala sekolah juga termasuk pribadi yang jujur dalam melaksanakan tugasnya, dalam artian kepela sekolah dapat dipercaya dalam menjalankan tugas dan kewajibannya. Kepala sekolah juga memberikan amanah atau tugas kepada para bawahan, dengan membagi tugas di sekolah dengan sebaik-baiknya. Pembagian tugas berdasarkan kompetensi yang dimiliki oleh guru dan staf. Berikut ini adalah cuplikan transkrip wawancara kepada Wakil Kepala Sekolah (Wakasek) Bidang Kesiswaan dan Wakasek Bidang Kurikulum.

Peneliti : Apakah kepala sekolah menjalin hubungan yang baik dengan seluruh warga sekolah?

Wakasek Kesiswaan : Setiap hari Jumat ada pertemuan rutin dengan para pimpinan sekolah, yakni kepala sekolah dan wakil kepala sekolah membahas tentang jalannya sekolah salam seminggu. Membahas apakah ada kesulitan. Dengan sifat kejujurannya Beliau tidak membeda-bedakan, jadi seorang kyai tahu persis bagaimana menempatkan diri dalam bertindak dan berperilaku.

Wakasek Kurikulum : Beliau sering sekali memberi nasihat-nasihat terkait dengan 
kehidupan yang harus dijalani oleh Bapak Ibu, misalnya bekerja itu harus ikhlas, digambarkan dengan apa namanya kegiatan yang pernah dijalankan oleh Rasulullah, misalnya seperti itu.

\section{Karakteristik Kepemimpinan Kepala Sekolah dalam Perspektif Psikologi}

Berdasarkan karakteristik psikologis kepemimpinan kepala sekolah menunjukkan pribadi yang tenang, santai, sabar, teliti, tidak mudah terpengaruh, dan kesadaran diri yang tinggi. Kepribadian yang ditampilkan kepala sekolah adalah pribadi yang tidak terburu-buru, tenang, tidak mudah dipengaruhi, dan setia. Karakteristik kepala sekolah menampilkan pribadi tidak mudah terpengaruh oleh kesan orang lain, adanya kesadaran dalam diri yang ditunjukan dengan sisi spiritual dari kepala sekolah yang kuat, dan banyak mewujudkan peristiwa kejiwaan dengan tindakan nyata. Berikut ini adalah cuplikan transkrip wawancara kepada Wakasek Bidang Kesiswaan.

Peneliti : Bagaimana sikap kepala sekolah dalam menyelesaikan masalah?

Wakasek Kesiswaan : Ya menurut saya dalam menyelesaikan masalah, Beliau itu, bukan santai tapi ya bersungguh-sungguh, apalagi kalau itu dari atasan, Beliau kelihatan bersungguhsungguh. Memang terkadang itu karena ya harus dengan waktu yang cepat, ada kesan seolah-olah gopoh (terburu-buru, tidak tenang), padahal sebenarnya itu karena kesungguhan.

Kepala sekolah memiliki sisi religius yang sangat kuat. Hal ini didukung oleh latar belakang kepala sekolah yang merupakan seorang pemimpin pondok pesantren. Kepala sekolah selalu berupaya meneladani sifat-sifat Nabi Muhammad dalam memimpin. Kepala sekolah memberikan nasihat kepada para bawahannya untuk bekerja secara ikhlas dan selalu menunaikan ibadah. Kepala sekolah dalam bertindak dan berucap berupaya berlandaskan pada hadist yang berkaitan dengan apa yang disampaikan. Selain itu, kepala sekolah juga berusaha untuk tidak menyalahkan orang lain apabila perintah yang diberikan kepada bahawan tidak dapat dilaksanakan sesuai dengan harapan. Berikut ini adalah cuplikan transkrip wawancara kepada kepala sekolah.

Kepala sekolah : Apabila ada orang yang tidak bersedia melakukan instruksi yang saya berikan, itu artinya saya kurang ibadah kepada Allah.

Peneliti : Bagaimana Bapak menghadapi guru atau staf yang kurang optimal dalam bekerja?

Kepala sekolah : Tentu setiap orang memiliki kemampuan masing-masing, pembagian pekerjaan harus sesuai dengan kompetensi, pekerjaan saya delegasikan dengan adil dan transparan.

\section{Model Kepemimpinan Kepala Sekolah dalam Perspektif Psikologi}

Temuan selanjutnya adalah kerangka model kepemimpinan kepala sekolah dalam perspektif psikologis mencerminkan kepemimpinan yang beratribut sanguin (aggressive) dan plegmatis (low profile). Model kepemimpinan pendidikan dikembangkan berawal dari atribut sifat-sifat kepemimpinan pendidikan. Berdasarkan atribut sifat-sifat kepemimpinan pendidikan yang tampak, kemudian kepemimpinan pendidikan yang berlandaskan pada perspektif psikologi. Adapun kerangka visual model kepemimpinan pendidikan berdasarkan perspektif psikologi tersebut diilustrasikan pada Gambar 1. 


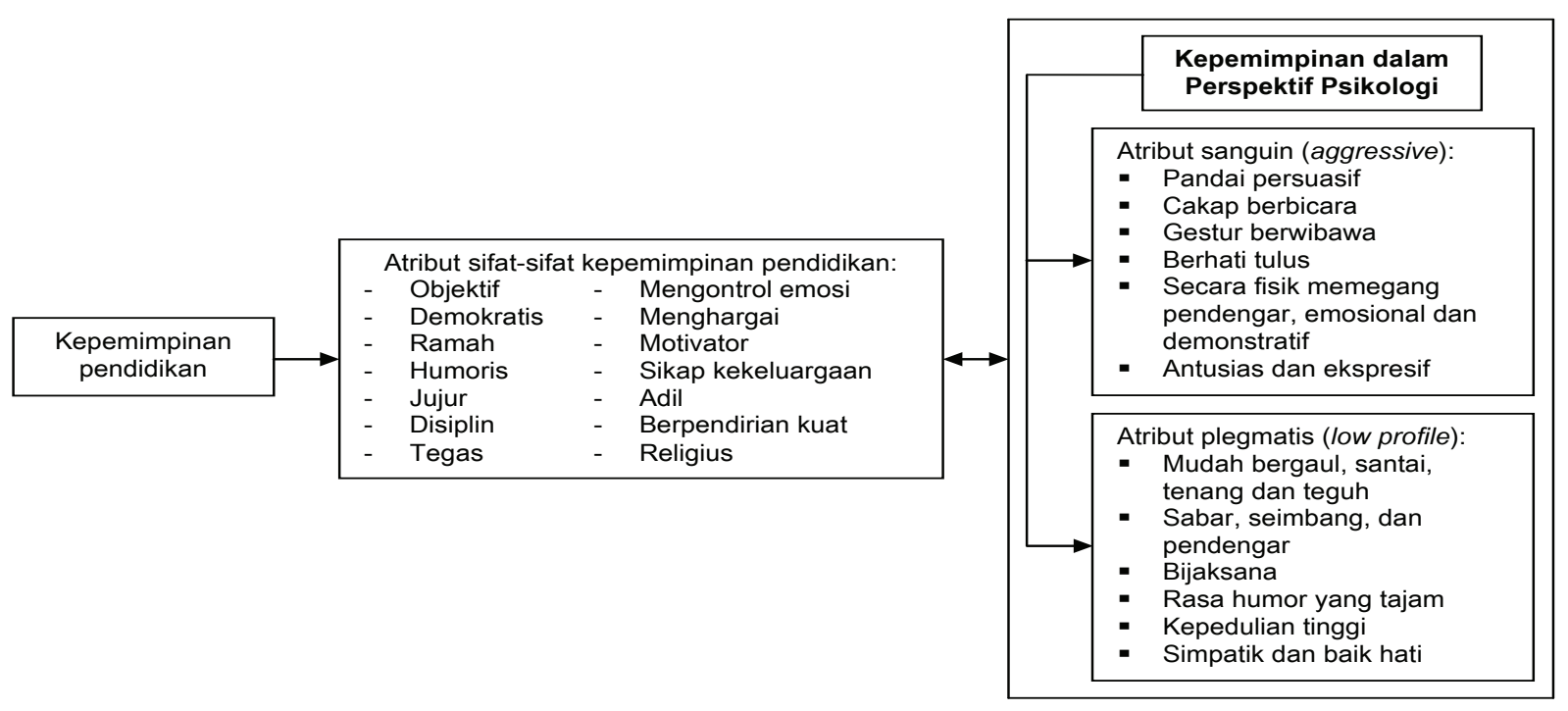

\section{Gambar 1 Kerangka Model Kepemimpinan Pendidikan dalam Perspektif Psikologi}

Kepemimpinan pendidikan yang berlandaskan pada atribut sifat-sifat kepemimpinan pendidikan merupakan reduksi karakter yang bersifat positif. Spirit dari atribut sifat-sifat kepemimpinan pendidikan adalah sifatsifat baik yang ideal melekat pada diri seorang pemimpin pendidikan. Pendidikan merupakan sumber dan acuan seorang pemimpin dalam menampilkan karakteristik atribut sifat-sifat kepemimpinan. Atribut sifat-sifat kepemimpinan pendidikan ini menekankan pada karakter kepribadian, sosial, fisik, atau intelektual seorang pemimpin. Berdasarkan atribut sifatsifat kepemimpinan inilah, akan menjadi atribut psikologis kepemimpinannya, manakala sifatsifat pemimpin telah melebur menjadi bagian dari kepribadiannya. Kepribadian dalam pandangan psikologi kepemimpinan meliputi seluruh aspek kehidupan seseorang, seperti intelegensi, bakat, minat, dan sifat seorang pemimpin. Kondisi psikologis seorang pemimpin mempengaruhi cara ia memimpin organisasinya.

Jika mengacu pada temuan, maka kepemimpinan yang efektif adalah kepemimpinan yang berlandaskan pada aspek psikologis seseorang. Gaya kepemimpinan dalam perspektif psikologis memiliki makna bahwa seorang pemimpin berinteraksi dengan bawahannya, harus memperhatikan perkembangan bawahannya. Sifat-sifat yang diterapkan sesuai dengan perkembangan bawahannya, sehingga akan tercipta komunikasi yang baik antara pemimpin dan bawahan. Ketepatan tersebut akan mempengaruhi model pembinaan yang dilakukan oleh seorang pemimpin kepada bawahnya. Keputusan yang diambil dipengaruhi oleh kematangan pribadi seorang pemimpin. Keputusan tersebut nantinya apakah juga dapat membantu proses perkembangan pribadi bawahannya. Komponen psikologis kepemimpinan meliputi: (1) atribut sanguin (aggressive), seperti pandai persuasif, cakap berbicara, gestur berwibawa, berhati tulus, secara fisik memegang pendengar; emosional dan demonstratif; dan antusias dan ekspresif; dan (2) atribut plegmatis (low profile), seperti mudah bergaul, santai, tenang dan teguh; sabar, seimbang, dan pendengar; bijaksana; rasa humor yang tajam; kepedulian tinggi; dan simpatik dan baik hati. 


\section{PEMBAHASAN}

\section{Sifat-sifat Kepemimpinan Kepala Sekolah}

Temuan penelitian menunjukkan bahwa atribut sifat-sifat kepemimpinan yang ditampilkan kepala sekolah adalah objektif, demokratis, ramah, humoris, jujur, disiplin, tegas, dapat mengontrol emosi, menghargai, motivator, memiliki sikap kekeluargaan pada semua anggota, adil, berpendirian kuat, dan religius. Kepemimpinan yang diterapkan oleh kepala sekolah dinilai sesuai dengan harapan para bawahannya. Hal ini dapat dilihat dari kemampuan kepala sekolah untuk memosisikan dirinya, bersikap demokratis, objektif, ramah, humoris, tidak memaksakan kehendak, serta mampu memperlakukan bawahan sesuai dengan pribadi bawahannya. Melalui hal-hal tersebut maka akan tercipta situasi kerja yang harmonis, dan akan mampu untuk bekerja secara efektif dan efisien. Apabila hal tersebut terwujud maka kepala sekolah akan mampu untuk mempengaruhi dan menggerakkan bawahannya agar bekerja sesuai dengan tujuan yang ditetapkan.

Temuan pertama selaras dengan teori kepemimpinan yang berlandaskan pada teori sifat (traits theory). Teori sifat memandang kepemimpinan sebagai suatu kombinasi sifat-sifat bawaan atau watak yang baik dan menitikberatkan pada kepemilikan karakter kepribadian, sosial, fisik, atau intelektual yang membedakan pemimpin dari yang bukan pemimpin (Gunawan dan Benty, 2017). Sifat-sifat pemimpin ialah ciri khas yang menunjukkan kepada sejumlah atribut individual seorang pemimpin yang membedakan sifat-sifat pemimpin efektif dengan pemimpin yang tidak efektif (Usman, 2007). Teori sifat beranggapan bahwa apa yang membuat seseorang pemimpin berhasil (efektif) adalah sumber dari personality (kepribadian) pemimpin itu sendiri sebagai seorang insan (Kusmintardjo, 1989). Hal senada dikemukakan oleh Hughes, dkk., (2002) yang menyatakan pemimpin efektif ialah pemimpin yang memiliki kepribadian dengan bercirikan pada sifat-sifat (traits) yang baik dan terdapat dalam lima faktor model kepribadian (five factor model of personality), yakni: kekacauan (surgency), pengakuan (agreeableness), dapat dipercaya (dependability), penyesuaian (adjustment), dan intelektualitas (intelectance).

Kouzes dan Posner (2002) berdasarkan hasil penelitiannya menyimpulkan sifat-sifat pemimpin yang baik adalah: (1) memandang jauh ke depan (visioner); (2) jujur; (3) cakap; dan (4) memberikan inspirasi. Sedangkan Yulk (2002) menyatakan bahwa sifat-sifat pemimpin yang efektif yaitu: (1) kebutuhan berafiliasi; (2); kestabilan emosi; (3) percaya diri; (4) integritas kepribadian; (5) orientasi pencapaian secara moderat; (6) energi kuat dan toleransi terhadap stres; (7) motivasi; (8) internal locus of control; dan(9) kedewasaan. Hal senada dikemukakan oleh Gibson, dkk., (2003) yang menyatakan sifat-sifat pemimpin yang efektif adalah: (1) kemampuan; (2) kepribadian; dan (3) motivasi. Miru (2006) menyatakan seorang pemimpin haruslah orang punya kejujuran; orang yang berfungsi akalnya; orang harus punya keberanian; dan orang yang kaya dalam arti luas. A number of studies have linked personality traits and attributes to leader ethical behaviour, providing a substantial empirical foundation for the argument that traits do matter in the prediction of ethical leadership phenomenon (Brown, dkk., 2005; Walumbwa dan Schaubroeck, 2009; Ozbag, 2016).

Traits are more likely to predict leadership when integrated in meaningful ways (Zaccaro, 2007). Kepemimpinan menjadikan suatu organisasi dapat bergerak secara terarah dalam upaya mencapai tujuan yang telah ditetapkan (Suharsaputra, 2016). Kepemimpinan pendidikan memiliki peran yang krusial dalam tata kelola dan penyelenggaraan bidang pendidikan, dan yang membedakan konsep kepemimpinan pendidikan dengan kepemimpinan dalam bidang lain ialah bahwa inti dari kepemimpinan pendidikan adalah mendidik (Gunawan, 2016a). Principals to focus on aspects of educational leadership by considering the values and ethics of leadership to create a climate of school work was good, make quick decisions and precise, confident, able to manage infrastructure, and exercise its authority as an educational leader (Kusumaningrum, dkk., 2016).

\section{Karakteristik Kepemimpinan Kepala Sekolah dalam Perspektif Psikologi}

Temuan penelitian menunjukkan bahwa berdasarkan perspektif psikologi, kepemimpinan yang dilakukan oleh kepala sekolah menunjukkan bahwa kepala sekolah merupakan sosok 
yang tenang, santai, sabar, teliti, tidak mudah terpengaruh, dan kesadaran diri yang tinggi. Hal ini menyebabkan kepala sekolah mampu menjadi sosok yang disegani dan menjadi panutan bagi para bawahannya. Sebagaimana pemimpin yang harus mampu untuk menggerakkan, mengarahkan, membimbing, melindungi, membina, memberikan teladan, memberikan dorongan, serta memberikan bantuan (Wahjosumidjo, 2013). Peran kepala sekolah dalam menampilkan sifatsifat dan perilaku kepemimpinan menjadi faktor penentu keberhasilan sekolah dalam mencapai tujuan (Gunawan, 2016c). The leadership of principal becomes decisive and crucial factor in developing the school quality (Gunawan, 2017a). Leadership model implemented principals become the key school to achieve the goals of the school (Gunawan, 2016b).

WawoRuntu (2003) berdasarkan hasil penelitiannya menyimpulkan bahwa faktorfaktor kepribadian seorang pemimpin yang dapat mempengaruhi kesuksesannya dalam memimpin organisasi adalah pembawa perubahan, komunikasi, kepemimpinan dalam pekerjaan, jejaring, pengembang orang lain, pengaruh, kerja kelompok, keragaman, pemakaian bahasa daerah, komitmen, kedisiplinan, menguasai teknologi informasi, keteladanan, kepamrihan kerja, keoptimisan, tindakan saling mengasihi, dan kekonsistenan. Selain itu, motivasi bawahan merupakan hal penting yang harus diketahui oleh seorang pemimpin, agar pemimpin dapat mempengaruhi mereka untuk ikut dalam program perubahan organisasi yang digagas oleh seorang pemimpin. A better understanding of the change agent's psychological motivations and her/his collaboration with other employees may contribute to the understanding of how to increase the social propinquity within companies (Witjes, 2015).

Leadership involves motivating others to work collaboratively in the pursuit of a common goal (Vroom dan Jago, 2007). Leaders emerge in a system that also involves willing followers and groups, express core values, display creativity and resilience, and in a sense are performance artists (Bennis, 2007). A systems model of leadership, provides an understanding of leadership as a set of decision processes embodying wisdom, intelligence, and creativity, as well as other higher cognitive processes (Sternberg,
2007). Ramadhani (2017) berdasarkan hasil penelitiannya psikologis dan jiwa seseorang mempengaruhi keputusan yang harus dibuatnya. Spiritual leadership significantly correlated with leadership effectiveness, as assessed by their staff, was significant after controlling for organization variables (organization size and growth) and personality (Amram, 2009).

Kepemimpinan profetik yang dilakukan oleh kepala sekolah dapat dilihat dari cara kepala sekolah dalam bertindak dan mengambil keputusan, dimana kepala sekolah selalu meneladani kepemimpinan yang dilakukan oleh Rasulullah Muhammad. Keteladanan yang dapat diambil dari Rasulullah Muhammad adalah kuatnya iman, berani, sabar, tabah, dan berakhlak mulia (Rivai dan Arifin, 2009). Berbagai upaya yang dilakukan kepala sekolah dalam mencapai tujuan pendidikan yang telah dicapai, kepala sekolah selalu berupaya agar mampu bersikap sebagaimana kepemimpinan Rasullah. Adapun diantaranya adalah bekerja dengan ikhlas, tidak marah ketika ada bawahan yang mengecewakan, memberikan nasihat, dan motivasi melalui hadist-hadist. Sebagaimana dalam konteks organisasi pendidikan Islam, kepemimpinan merupakan suatu proses dalam mencapai tujuan yang telah disepakati bersama sesuai etikquranik (Baharuddin dan Umiarso, 2016). The leadership of principalship is a factor that affects the performance of teachers to teach (Gunawan, 2017b).

\section{Model Kepemimpinan Kepala Sekolah dalam Perspektif Psikologi}

Temuan penelitian menunjukkan model kepemimpinan kepala sekolah yang efektif dalam perspektif psikologis adalah seorang kepala sekolah yang mencerminkan kepemimpinan beratribut sanguin dan plegmatis (Gambar 1). Atribut sanguin merupakan karakter seorang pemimpin yang memiliki sifat agresif (aggressive). Sikap agresif yang dimaksud adalah sikap yang memiliki semangat dan penuh inisiatif. Sanguine types greater optimism (Howart, 1988). Atribut plegmatis merupakan karakter seorang pemimpin yang memiliki sifat rendah hati (low profile). Phlegmatics less state anxiety and least depression (Howart, 1988). Perpaduan sifat sanguen dan plegmatis menjadikan seseorang 
yang bekerja keras, sedikit bicara, banyak bertindak, visioner, dan tetap rendah hati. Kant membagi kepribadian (personality) menjadi dua, yaitu: (1) temperament of emotions that included sanguine; dan (2) temperament of activity that included phlegmatics (Vorkapić, 2011).

Sanguine (stable extraverts) as sociable, lively, carefree, leadership, outgoing, talkative, responsive and easygoing (Revelle, dkk., 2011; Vorkapić, 2011). Sanguinis mempunyai sifat khas hidup, ramah, lekas bertindak (Sujanto, dkk., 2001). Some strengths of the sanguine temperament are: (1) he is enjoys life; (2) he is optimistic; (3) he is friendly; (4) he is compassionate; and (5) he is extrovert (Cantrell, 2001). The characteristic of sanguine is strong balanced mobile and stable extravert (Ruch, 1992). Ciri-ciri seorang sanguinis dari segi emosi, yaitu kepribadian yang menarik, suka bicara, rasa humor yang hebat, ingatan kuat, secara fisik memukau pendengar, emosional dan demonstratif, antusias dan ekspresif, periang dan penuh semangat, penuh rasa ingin tahu, hidup dimasa sekarang, berhati tulus (Hasanah, 2014).

Phlegmatic (stable introverts) as passive, careful, thoughtful, peaceful, controlled, reliable, even-tempered and calm (Revelle, dkk., 2011; Vorkapić, 2011). Sifat khas plegmatis adalah tidak suka terburu-buru (calm, tenang), tak mudah dipengaruhi, dan setia (Hasanah, 2014). Some strengths of flip phlegmatic are: (1) he is witty; (2) he is easy going; (3) he is dependable; (4) he is very practical and efficient; and (5) he is neat (Cantrell, 2001). Atribut plegmatis memiliki sifat baik hati, pribadinya tenang rendah hati dan juga penyabar, terlihat kalem, mempunyai daya humor yang tinggi, dan menyenangkan untuk diajak gaul (Karina, 2015). Ciri-ciri seorang plegmatis dari segi emosi, yaitu kepribadian rendah hati, mudah bergaul dan santai, diam, tenang, sabar, baik keseimbangannya, hidup konsisten, tenang tetapi cerdas, simpatik dan baik hati, menyembunyikan emosi, dan bahagia menerima kehidupan (Hasanah, 2014).

\section{KESIMPULAN DAN SARAN}

\section{Kesimpulan}

Berdasarkan hasil penelitian dapat disimpulkan bahwa kepala sekolah menerapkan gaya kepemimpinan profetik. Sifat-sifat kepemimpinan yang nampak pada kepala sekolah yaitu religius, objektif, demokratis, ramah, humoris, dan jujur. Berdasarkan perspektif psikologi, kepala sekolah menampilkan kepribadian yang tenang, tidak suka terburuburu, sabar, teliti, tidak emosional, mudah tersenyum dan bersuara pelan. Berdasarkan emosional diketahui kepala sekolah menampilkan pemimpin yang berpendirian kuat, kesadaran diri yang tinggi dan menghubungkan dengan aspek religi. Berdasarkan hal tersebut dapat diketahui bahwa kepala sekolah merupakan seorang pemimpin yang memiliki kepribadian sabar, teliti, tenang, dan tidak emosional. Nilai religius yang sangat kuat dari diri kepala sekolah nampak pada beribadah tepat waktu, berpedoman pada keyakinan berdasarkan nilai-nilai religi, dan mengajarkan bekerja secara ikhlas dengan diniati ibadah.

\section{Saran}

Berdasarkan temuan penelitian, saran yang diajukan kepada Kepala Dinas Pendidikan Kota Malang adalah agar menyelenggarakan pendidikan dan pelatihan kepemimpinan kepala sekolah yang berbasis psikologi kepemimpinan. Bagi Kepala SMA Kota malang agar menerapkan gaya kepemimpinan pendidikan dengan memperhatikan aspek psikologi. Perilaku kepemimpinan kepala sekolah yang demikian akan berdampak positif bagi jalinan komunikasi antara kepala sekolah dengan para guru dan staf. Saran bagi peneliti selanjutnya agar menjadikan temuan penelitian ini sebagai referensi dalam penelitiannya tentang kepemimpinan dan melakukan kajian variabel kepemimpinan dengan variabel lain. Bagi peneliti selanjutnya juga disarankan menggunakan pendekatan penelitian yang berbeda dari penelitian ini, yakni dengan metode kuantitatif.

\section{DAFTAR RUJUKAN}

Amram, J. Y. 2009. The Contribution of Emotional and Spiritual Intelligences to Effective Business Leadership. Disertasi tidak diterbitkan. California: Institute of Transpersonal Psychology.

Baharuddin, dan Umiarso. 2016. Kepemimpinan Pendidikan Islam: Antara Teori dan Praktik. Jogjakarta: Ar-Ruzz Media.

Bennis, W. 2007. The Challenges of Leadership in the Modern World: Introduction to the Special Issue. American Psychologist, 62(1), 2-5. 
Brown, M. E., Trevino, L. K., dan Harrison, D. A. 2005. Ethical Leadership: A Social Learning Perspective for Construct Development and Testing, Organizational Behavior and Human Decision Processes. Journal of Business Ethics, 97: 117-134.

Cantrell, P. E. 2001. A Study of Temperament: From a Biblical Viewpoint. Pennsylvania: Eleven Lessons.

Gibson, J. L., Ivancevich, J. M., Donnelly, J. H., dan Konopaske, R. 2003. Organizations: Behavior, Structure, Processes. New York: McGraw Hill, Inc.

Gunawan, I. 2014a. Metode Penelitian Kualitatif: Teori dan Praktik. Jakarta: PT Bumi Aksara.

Gunawan, I. 2014b. Pengaruh Supervisi Pengajaran dan Kemampuan Guru Mengelola Kelas terhadap Motivasi Belajar Siswa. Ilmu Pendidikan Jurnal Kajian Teori dan Praktik Kependidikan, 41(1), 44-52.

Gunawan, I. 2015a. Mengembangkan Kepemimpinan Kepala Sekolah Berbasis Nilai dan Etika. Proceeding National Seminar and International Conference Scientific Forum-Faculty of Education Department of Science Educatioin (FIP-JIP), Fakultas Ilmu Pendidikan Universitas Negeri Gorontalo, Gorontalo, 9-11 September, hlm. 302-312.

Gunawan, I. 2015b. Pengaruh Kepemimpinan Transformasional dan Kepuasan Kerja terhadap Perilaku Kewargaan Organisasi Guru Sekolah Dasar. Premiere Educandum, 5(1), 59-81.

Gunawan, I. 2015c. Values and Ethics in Educational Leadership: An Idea of Character Building of Students. Conference Proceedings Character Education in Indonesia Concepts and Applications in Primary Schools, IKIP PGRI MADIUN, 9 Juni, 1-13.

Gunawan, I. 2016a. Merevitalisasi Kepemimpinan Pancasila dalam Bidang Pendidikan. Prosiding Seminar Nasional Penguatan Manajemen Pendidikan di Era Kompetisi Global, Jurusan Administrasi Pendidikan Universitas Negeri Malang, 12 Maret, hlm. 67-84.

Gunawan, I. 2016b. Model of Educational Leadership in the Implementation of Curriculum 2013. Proceedings The $4^{\text {th }}$ International Conference Language, Society, and Culture in Asian Contexts (LSCAC 2016) on Cultivating and Casting Asian Diversities: Empowering the Asians, 24-25 Mei, hlm. 1109-1118.

Gunawan, I. 2016c. Pasaran: Menggali Nilai-nilai Permainan Tradisional dalam Mengembangkan Sifat-sifat Kepemimpinan Pendidikan. Jurnal Studi Sosial, 8(1), 55-64.
Gunawan, I. 2017a. Instructional Leadership Profile of Junior High School's Principal (A Case Study of Junior High School in Malang). International Research-Based Education Journal, 1(1), 64-68.

Gunawan, I. 2017b. Instructional Management in Indonesia: A Case Study. Journal of Arts, Science and Commerce, 8(1), 99-107.

Gunawan, I., dan Benty, D. D. N. 2017. Manajemen Pendidikan: Suatu Pengantar Praktik. Bandung: Alfabeta.

Hasanah, I. I. 2014. Kepribadian Manusia, (Online), (http://digilib.uinsby.ac.id/1964/5/Bab\%202. pdf), diakses 2 Desember 2016.

Howart, E. 1988. Mood Differences between the Four Galen Personality Types: Choleric, Sanguine, Phlegmatic, Melancholic. Personality and Individual Differences, 9(1), 173-175.

Hughes, R. L., Ginnett, R. C., dan Curphy, G. J. 2002. Leadership Enchancing: The Lessons Experience. New York: McGraw Hill, Inc.

Hussain, S. T., Lei, S., Akram, T., Haider, M. J., Hussain, S. H., dan Ali, M. 2016. Kurt Lewin's Process Model for Organizational Change: The Role of Leadership and Employee Involvement: A Critical Review. Journal of Innovation and Knowledge, 46(2), 1-7.

Karina, S. 2015. Mengenal Kepribadian Manusia (Melankolis \& Plegmatis), (Online), (http://karin.student. akademitelkom.ac.id/wp-content/ uploads/kalins-pdf/singles/mengenalkepribadian-manusia-melankolisplegmatis.pdf), diakses 23 Mei 2016.

Kouzes, J. M., dan Posner, B. Z. 2002. The Leadership Challenge. San Francisco: Jossey-Bass Publishers.

Kusmintardjo. 1989. Kepemimpinan dalam Pendidikan. Dalam Soekarto, I., dan Soetopo, H., (Eds.), Administrasi Pendidikan (hlm. 251-279). Malang: Penerbit IKIP Malang.

Kusumaningrum, D. E., Sumarsono, R. B., dan Gunawan, I. 2016. Principal Empowerment Through Soft System Methodology Approach. Proceeding International Conferences on Education and Training, $2^{\text {nd }}$ ICET Theme: Improving the Quality of Education and Training Through Strengthening Networking, 4-6 November, hlm. 205-211. 
Messick, D. M., dan Kramer, R. M. 2005. Introduction: New Approaches to the Psychology of Leadership. Dalam Messick, D. M., dan Kramer, R. M., (Eds.)., The Psychology of Leadership: New Perspectives and Research (hlm. 1-10). New Jersey: Lawrence Erlbaum Associates, Publishers.

Miles, M. B., Huberman A. M., dan Saldana, J. 2014. Qualitative Data Analysis: A Methods Sourcebook. New York: SAGE Publications, Inc.

Miru, S. 2006. Kajian Kepemimpinan Kaitannya dengan Total Quality Management Perusahaan Cold Storage Eksportir Udang di Makassar. Analisis, 3(1), 53-60.

Ozbag, G. K. 2016. The Role of Personality in Leadership: Five Factor Personality Traits and Ethical Leadership. 12 ${ }^{\text {th }}$ International Strategic Management Conference (ISMC 2016), 28-30 Oktober, Antalya, Turkey, (Online), Procedia Social and Behavioral Sciences, (http://www. sciencedirect.com), diakses 20 Maret 2017.

Ramadhani, A. 2017. Logika Hubungannya dengan Psikologi dan Kepemimpinan, (Online), (http://informatika.stei.itb.ac.id/ rinaldi. munir/Matdis/2007-2008/Makalah/ MakalahIF2153-0708-033.pdf), diakses 23 Februari 2017.

Revelle, W., Wilt, J., dan Condon, D. M. 2011. Individual Differences and Differential Psychology: A Brief History and Prospect. Dalam Chamorro-Premuzic, T., VonStumm, S., dan Furnham, A., (Eds.)., The Willey-Blackwell Handbook of Individual Differences (hlm. 3-38). London: Blackwell Publishing, Ltd.

Rivai, V., dan Arifin, A. 2009. Islamic Leadership: Membangun Super Leadership melalui Kecerdasan Spiritual. Jakarta: PT Bumi Aksara.

Ruch, W. 1992. Pavlov's Types of Nervous System, Eysenck's Typology and the Hippocrates-Galen Temperaments: An Empirical Examination of the Asserted Correspondence of Three Temperament Typologies. Personality and Individual Differences, 13(12), 1259-1271.

Sternberg, R. J. 2007. A Systems Model of Leadership: WICS. American Psychologist, 62(1), 34-42.

Suharsaputra, U. 2016. Kepemimpinan Inovasi Pendidikan: Mengembangkan Spirit Enterpreneurship Menuju Learning School. Bandung: PT Refika Aditama.
Sujanto, A., Lubis, H., dan Hadi, T. 2001. Psikologi Kepribadian. Jakarta: PT Bumi Aksara.

Ulfatin, N. 2015. Metode Penelitian Kualitatif di Bidang Pendidikan: Teori dan Aplikasinya. Malang: Media Nusa Creative.

Usman, H. 2007. Faktor-faktor yang Mempengaruhi Perilaku Kepala Sekolah. Jurnal Tenaga Kependidikan, 2(3), 1-20.

Vorkapić, S. T. 2011. Electrophysiological Differences in Sanguine, Choleric, Phlegmatic and Melancholic. Romanian Journal of Psychology, Psychotherapy and Neuroscience, 1(2), 67-96.

Vroom, V. H., dan Jago, A. G. 2007. The Role of the Situation in Leadership. American Psychologist, 62(1), 17-24.

Wahjosumidjo. 2013. Kepemimpinan Kepala Sekolah: Tinjauan Teoretik dan Permasalahannya. Jakarta: PT Rajagrafindo Persada.

Walumbwa, F. O., dan Schaubroeck, J. 2009. Leader Personality Traits and Employee Voice Behavior: Mediating Roles of Ethical Leadership and Work Group Psychological Safety. Journal of Applied Psychology, 94(5), 1275-1286.

WawoRuntu, B. 2003. Determinan Kepemimpinan. Makara, Sosial Humaniora, 7(2), 71-81.

Witjes, S. 2015. A New Psychology for Sustainability Leadership: The Hidden Power of Ecological Worldviews. Journal of Cleaner Production, 45(2), 1-2.

Yulk, K. 2001. Leadership in Organization. New Jersey: Prentice Hall Inc.

Yukl, G. 2002. Leadership in Organizations. Upper Sadle River, New Jersey: Prentice Hall.

Zaccaro, S. J. 2007. Trait-Based Perspectives of Leadership. American Psychologist, 62(1), 6-16.

Zainal, V. R., Hadad M. D., dan Ramly, M. 2014. Kepemimpinan dan Perilaku Organisasi. Jakarta: PT Rajagrafindo Persada. 